Pesq. Vet. Bras. 25(3):179-187, jul./set. 2005

\title{
Intoxicação experimental por Manihot glaziovii (Euphorbiaceae) em caprinos ${ }^{1}$
}

\author{
Sara Lucena Amorim² ${ }^{2}$ Rosane M.T. Medeiros ${ }^{2 *}$ e Franklin Riet-Correa ${ }^{2}$
}

\begin{abstract}
Amorim S.L., Medeiros R.M.T. \& Riet-Correa F. 2005. [Experimental poisoning by Manihot glaziovii (Euphorbiaceae) in goats.] Intoxicação experimental por Manihot glaziovii (Euphorbiaceae) em caprinos. Pesquisa Veterinária Brasileira 25(3):179-187. Centro de Saúde e Tecnologia Rural, UFCG, Campus de Patos, 58700-000 Patos, PB, Brazil. E-mail: rmtmed@cstr.ufcg.edu.br

Samples of fresh, dried and partially dried leaves of Manihot glaziovii Muell. Arg. were administered orally to Moxotó goats in single doses up to $12 \mathrm{~g} / \mathrm{kg}$ body weight (bw). The cyanide content of the plant samples was determined by the picrosodic paper test. The plant was collected from January to June 2004 . When the goats with clinical signs were in lateral recumbency, they were treated intravenously with $50 \mathrm{ml} / 100 \mathrm{~kg} / \mathrm{bw}$ of a $20 \%$ aqueous solution of sodium tiosulfate. Three experiments were performed. In Experiment 1, the plant was given immediately after collection to six goats; two ingested the plant after been ground and four ingested the plant without having been ground. In Experiment 2, the plant was maintained in the shade, in open air or inside plastic bags. The plastic bags were changed daily. The plant kept in plastic bags was given to 18 goats, 4, 8, 12, 16, 20, 24, 48, 72, 96 and 120 hours after collection. The plant kept in the open air was given to 13 goats, 4, 24, 48, 72 and 96 hours and 9, 10, 23 and 30 days after collection. In Experiment 3, the previously ground plant kept in the open air or inside plastic bags was administered 4, 8, 12, 16, 20, 24, 48, 72 and 96 hours after collection. Seventeen goats received the plant kept in plastic bags, and 16 goats the plant left in the open air. In Experiments 2 and 3, two or three goats were used for each period after collection, and the plant was given until the loss of its toxicity. Forty goats were used as controls for evaluation of the cardiac and respiratory frequencies. In Experiment 1, the ground and not ground plant had similar toxicity. In Experiment 2, the plant kept in the open air maintained its toxicity during the whole experiment (30 days), and the plant kept inside the plastic bags was toxic until 96 hours after collection. In Experiment 3, the ground plant, left in the open air or kept inside plastic bags, was toxic for 72 hours after collection. In all experiments clinical signs were characteristic of cyanide poisoning. All poisoned goats were treated successfully. In conclusion, Manihot glaziovii, which is used as forage in northeastern Brazil, should be ground and left for at least 96 hours in the open air before feeding to animals. The plant for preparing hay should be previously ground, and the hay should be given to animals also only 96 hours after its preparation.
\end{abstract}

INDEX TERMS: Poisonous plants, plant poisoning, Manihot glaziovii, Euphorbiaceae, cyanogenic plants, hydrocyanic acid, goats.

${ }^{1}$ Recebido em 25 de fevereiro de 2005.

Aceito para publicação em 10 de março de 2005.

Parte da tese da primeira autora no Curso de Mestrado em Medicina Veterinária de Pequenos Ruminantes da Universidade Federal de Campina Grande (UFCG).

${ }^{2}$ Centro de Saúde e Tecnologia Rural, UFCG, Campus de Patos, 58700-000 Patos, PB. *Autor para correspondência. E-mail: mrtmed@cstr.ufcg.edu.br
RESUMO.- Amostras das folhas frescas, murchas e dessecadas de Manihot glaziovii Muell. Arg. foram administradas manualmente por via oral a caprinos da raça Moxotó, em dosagens únicas de até $12 \mathrm{~g} / \mathrm{kg}$ de peso do animal. O teste do papel picrosódico foi realizado para determinar a presença do ácido cianídrico nas amostras de planta. A colheita da planta foi realizada no período de janeiro a junho de 2004. Os animais que 
apresentaram sinais clínicos foram tratados após apresentarem queda e permanência em decúbito lateral, com uma solução aquosa de tiossulfato de sódio a $20 \%$ na dose de $50 \mathrm{ml} /$ $100 \mathrm{~kg}$ por via endovenosa. $O$ presente trabalho foi dividido em três experimentos. No Experimento 1, a planta recém colhida foi fornecida a 6 caprinos, sendo que 4 receberam a planta não triturada e 2 a planta triturada. A planta foi triturada em uma forrageira, sem peneira. No Experimento 2, a planta não triturada permaneceu na sombra, em local ventilado, acondicionada fora e dentro de saco plástico, os quais eram trocados todos os dias. A planta armazenada dentro de sacos plásticos foi administrada a 18 caprinos, nos períodos de $4,8,12,16$, $20,24,48,72,96$ e 120 horas após a colheita e a armazenada fora de saco plástico foi administrada a 13 caprinos, nos períodos de 4, 24, 48, 72 horas e 9, 10, 23 e 30 dias após a colheita. No Experimento 3, a planta triturada e conservada dentro e fora de saco plástico foi administrada em diferentes períodos após a colheita $(4,8,12,16,20,24,48,72$ e 96 horas). Foram utilizados 33 animais (Exp. 3), 17 para a planta conservada dentro do saco plástico e 16 animais para a planta conservada fora do saco plástico. Nos Experimentos 2 e 3 foram utilizados um ou dois caprinos por cada período de administração. Foram utilizados 40 caprinos como controle, nos quais foram avaliadas a temperatura e as frequiências cardíaca e respiratória. No Experimento 1, as amostras da planta triturada e não triturada apresentaram toxicidade semelhante. No Experimento 2, a planta conservada fora de saco plástico manteve a toxicidade durante todo o experimento (30 dias), enquanto que a conservada dentro de saco plástico manteve a toxicidade por até 96 horas após a colheita. No Experimento 3, a planta triturada conservada dentro e fora de saco plástico manteve a toxicidade por até 72 horas após a colheita. Em todos os experimentos, os caprinos apresentaram sinais clínicos de intoxicação cianídrica. Todos os animais intoxicados se recuperaram clinicamente imediatamente após o tratamento. Conclui-se que para a alimentação de caprinos com Manihot glaziovii a planta deve ser triturada imediatamente após a colheita e conservada fora de sacos plásticos e só deve ser administrada após 96 horas. $\mathrm{O}$ feno deve ser produzido após a moagem da planta e administrado também somente após 96 horas.

TERMOS DE INDEXAÇÃO: Plantas tóxicas, intoxicação por planta, Manihot glaziovii, planta cianogênica, ácido cianídrico, caprinos.

\section{INTRODUÇÃO}

No Brasil são conhecidas mais de 80 espécies de plantas tóxicas para herbívoros (Tokarnia et al. 2000) que causam perdas econômicas, por conceito de mortes de animais, estimadas entre 160 e 224 milhões de dólares (Riet-Correa \& Medeiros 2001). No entanto, se desconhecem a freqüiência e a importância das intoxicações por plantas cianogênicas. Isto porque são raras as descrições de surtos espontâneos dessas intoxicações.

São consideradas plantas cianogênicas aquelas que contêm como princípio ativo o ácido cianídrico $(\mathrm{HCN})$, um líquido incolor, muito volátil, considerado como uma das substâncias mais tóxicas que se conhecem (Tokarnia et al. 2000). Nas plantas, o HCN encontra-se ligado a glicosídeos cianogênicos, sendo ne- cessário à hidrólise destes para a sua liberação. Os glicosídeos cianogênicos tem sido constatados em plantas de muitas famílias, principalmente rosáceas, leguminosas, gramíneas, aráceas, passifloráceas e euforbiáceas. Além das plantas, o HCN também é encontrado em cogumelos, fungos e bactérias (Diaz et al.1978, Tokarnia et al. 2000). Tokarnia et al. (2000) consideram que há mais de 1.000 espécies vegetais cianogênicas, enquanto que Vennesland et al. (1982) mencionam cerca de 2.000 espécies vegetais cianogênicas. No entanto, a maioria delas não causa danos, em função da sua baixa palatabilidade e/ou seu baixo teor de glicosídeos cianogênicos (Tokarnia et al. 2000).

No Brasil, as principais plantas cianogênicas de interesse econômico são: Manihot spp (Euphorbiacae), distribuída por todo o nordeste do Brasil; Anadenanthera colubrina (Vell.) Bren. var. cebil (Gris.) Reis Altschul (sinonímia: Anadenanathera macrocarpa (Benth.) Speg. e Piptadenia macrocarpa Benth.) pertencente à subfamília Leguminosae Mimosoideae, uma árvore conhecida popularmente como angico-preto que se encontra distribuída em todo Nordeste Brasileiro; Piptadenia viridiflora (Kunth.) Benth., também da Região Nordeste, conhecida popularmente como espinheiro e surucu; Sorghum spp da família Gramineae, com o nome popular de sorgo, que encontra-se distribuído por todo o Brasil; e Prunus spp pertencentes à família Rosaceae, conhecida popularmente como pessegueiro-bravo, que se encontra nas regiões Sul e Sudeste (Canella et al. 1968, Gava 1992, Mendez 1993, Tokarnia et al. 1994, 1999, 2000).

No Nordeste do Brasil, o gênero Manihot é conhecido como causador de mortes em ruminantes e encontram-se distribuídos desde o Piauí até a Bahia (Tokarnia et al. 2000). Manihot esculenta Crantz (mandioca) é a mais conhecida, porém outras espécies, conhecidas como maniçobas ocorrem em áreas nativas ou são cultivadas como forrageiras. No Semi-árido do Nordeste, além de M. esculenta encontram-se oito espécies do gênero Manihot: (1) Manihot glaziovii Muell. Arg. (maniçoba-do-Ceará), (2) Manihot dichotoma Ule (maniçoba-de-jequié) (3) Manihot cearulescens Pohl (maniçoba do Piauí) (4) Manihot diamantinensis Allem (mandiocabrava) (5) Manihot jacobinensis Muell. Arg. (mandioca-brava), (6) Manihot janiphoides Muell. Arg. (mandioca-brava), (7) Manihot maracasensis Ule (maniçoba) e (8) Manihot sp (mandioca-Tapuio). Além das espécies de Manihot acima mencionadas, existe no semiárido nordestino, um híbrido natural entre maniçobas e mandiocas, conhecido por vários nomes, entre os quais se destacam Prinunça, Pornuncia, Mandioca-de-Sete-Anos e Maniçoba-de-Jardim, muito utilizado atualmente como planta ornamental e que foi utilizado também para a produção de farinha (Araújo et al. 2001). As intoxicações por essas espécies ocorrem quando animais famintos invadem culturas, quando as primeiras chuvas são seguidas de uma estiagem de vários dias e os animais ingerem as plantas murcha e seca, quando ruminantes são alimentados com as folhas frescas e/ou tubérculos sem os devidos cuidados quanto à eliminação do princípio ativo, ou durante a fabricação da farinha e outros produtos, onde os animais têm acesso a manipueira, líquido rico em $\mathrm{HCN}$, resultante da compressão da massa ralada das raízes da mandioca. (Canella et al. 1968, Tokarnia et al. 2000).

Na Paraíba, as plantas que tem sido responsabilizada por causarem intoxicação por ácido cianídrico são Sorghum spp, 
Anandenanthera colubrina e Manihot spp (Medeiros et al. 2000). Experimentos realizados com amostras de Anandenanthera colubrina, coletadas no município de Patos, causaram intoxicação por $\mathrm{HCN}$ na dose de $10 \mathrm{mg}$ por $\mathrm{kg}$ de peso do animal (Medeiros et al. 2000). Amorim et al. (2004) reproduziram a intoxicação cianídrica em amostras de Manihot glaziovii e de Anadenanthera colubrina com doses de 5 a $10 \mathrm{~g} / \mathrm{kg}$ em bovinos na Paraíba.

Apesar de numerosos veterinários e produtores responsabilizarem Manihot spp por surtos de mortalidade em bovinos e caprinos, a importância tóxica dessas plantas permanece desconhecida e não se conhecem fatores epidemiológicos que possam ser importantes para a ocorrência da intoxicação. Os estudos anteriores sobre a toxicidade de Manihot spp foram realizados somente em bovinos, no entanto, produtores de caprinos relatam casos de intoxicação nesses animais. Por outro lado, as diferentes espécies de Manihot estão sendo cada vez mais utilizadas como forrageiras na alimentação de caprinos e ovinos. Essa utilização é baseada no fato de que depois de coletada, fenada ou ensilada, a planta perde a toxicidade.

Considerando esses fatos é evidente a necessidade de estudar as plantas cianogênicas nativas da Paraíba e estabelecer as condições nas quais ocorre a intoxicação. Os objetivos deste trabalho foram: determinar os fatores epidemiológicos que determinam a ocorrência de intoxicação por Manihot glaziovii, em caprinos; determinar a toxicidade de M. glaziovii em diferentes épocas do ano; e determinar a perda da toxicidade da espécie $M$. glaziovii após a colheita e após moagem.

\section{MATERIAL E MÉTODOS}

Os experimentos foram realizados nas dependências do Hospital veterinário da Universidade Federal de Campina Grande (UFCG), Campus de Patos-PB, durante o período de janeiro a junho de 2004. Folhas frescas, parcialmente dessecadas (murchas e secas) de Manihot glaziovii Muell. Arg., árvore pertencente a família Euphorbiaceae (Fig.1), foram administradas manualmente por via oral a 44 caprinos da raça Moxotó, com dosagem única de até $12 \mathrm{~g} / \mathrm{kg}$. Alguns caprinos foram utilizados mais de uma vez, totalizando 104 intoxicações. Caso os animais apresentassem sinais clínicos de intoxicação cianídrica antes de consumirem a dosagem prevista, suspendia-se a

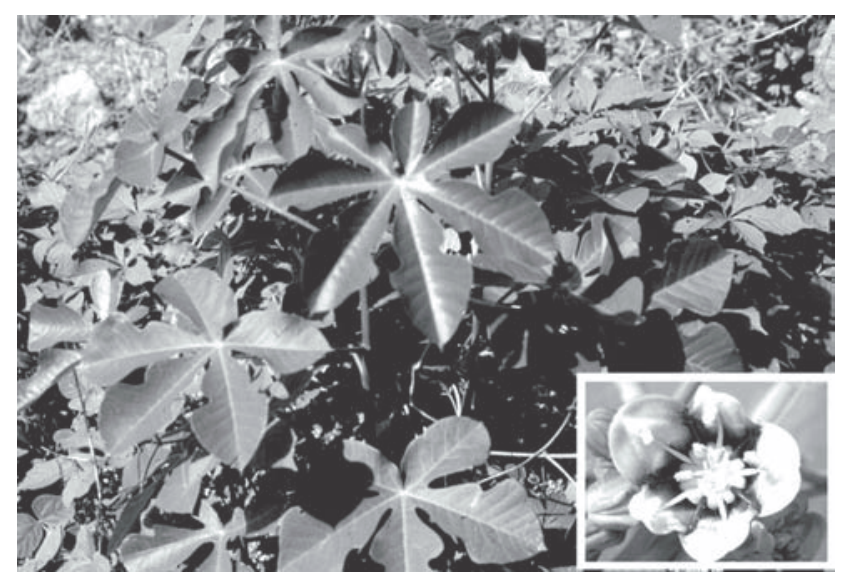

Fig. 1. Manihot glaziovii Muell. Arg. (Euphorbiaceae). Município de Teixeira, Paraíba. Inflorescência inserida no canto inferior direito. administração da planta, calculava-se a sobra e a quantidade ingerida até aquele momento era considerada a dose tóxica.

Antes dos experimentos os caprinos experimentais foram submetidos a jejum de 24 horas e pesados, para a determinação da dose a ser ingerida. $\mathrm{O}$ teste do papel picrosódico foi realizado para determinar a presença do ácido cianídrico nas diferentes amostras da planta. Preparou-se este papel-reagente, molhando-se tiras de papel filtro em uma solução composta de $5 \mathrm{~g}$ de carbonato de sódio e 0,5g de ácido pícrico dissolvidos em água destilada para $100 \mathrm{ml}$ de solução. As tiras de papel assim preparadas apresentavam-se amarelas. As amostras das plantas foram esmagadas e colocadas em um vidro fechado, fixando a tira do papel já seca na tampa do vidro, de modo que ficasse suspensa livremente acima do material. Em seguida manteve-se o vidro em posição vertical, à temperatura ambiente. Para determinar a presença de $\mathrm{HCN}$ observava-se a mudança de cor do papel, primeiramente da cor amarela para laranja e posteriormente para vermelho tijolo. A intensidade da reação ao teste do papel picrosódico foi classificada em reação acentuada (quando o tempo de mudança de coloração para vermelho era de até 5 minutos), moderada (quando o tempo de mudança de coloração era de 5 a 10 minutos), leve (quando o tempo de mudança de coloração passava dos 10 minutos até 3 horas ou quando apenas mudava de coloração para o laranja), discreta (apenas quando mudava de coloração para o laranja após 3 horas) e sem reação (quando não ocorria nenhuma mudança de coloração).

A colheita da planta foi realizada no município de Teixeira, Paraíba, no período de janeiro a junho de 2004. A planta utilizada foi identificada pela Professora $\mathrm{M}^{\mathrm{a}}$ das Graças Marinho do Curso de Engenharia Florestal, Universidade Federal de Campina Grande, e exsicatas da mesma são mantidos no Departamento de Engenharia Florestal dessa Instituição.

Os animais foram acompanhados clinicamente observando-se o aparecimento dos sinais clínicos, como também se avaliando a temperatura e as frequiências cardíaca e respiratória. Os animais eram tratados quando caiam e permaneciam em decúbito lateral, com opistótono. Nesse momento aplicava-se uma solução aquosa de tiossulfato de sódio a $20 \%$ na dosagem de $50 \mathrm{ml} / 100 \mathrm{~kg}$ por via endovenosa. Nos animais que não apresentaram intoxicação cianídrica, também foi administrado o antídoto como forma de precaução. Em caso de morte era realizada a necropsia e coletavamse amostras de fígado, pulmão, rim, glândula salivar, coração e sistema nervoso central. Essas amostras eram fixadas em formol a $10 \% \mathrm{e}$ posteriormente realizado o exame histopatológico. $\mathrm{O}$ presente trabalho foi dividido em três experimentos:

Experimento 1 (Quadro 1). A planta recém colhida foi fornecida a seis caprinos, sendo a planta não triturada a quatro e a planta triturada a dois. A trituração era feita em uma forrageira (picadeira), sem peneira, após uma a duas horas de colhida, tempo utilizado para a colheita e transporte da planta.

Experimento 2 (Quadros 2 e 3). Após a colheita a planta não triturada permaneceu na sombra, em local ventilado, acondicionada fora e dentro de saco plástico, os quais eram trocados todos os dias para evitar o aparecimento de fungos. A planta armazenada dentro de sacos plásticos foi administrada a 18 caprinos, nos períodos de 4 , $8,12,16,20,24,48,72,96$ e 120 horas após a colheita. A planta armazenada fora do saco plástico foi administrada a 13 caprinos, nos períodos de 4, 24, 48, 72 horas e 9, 10, 23 e 30 dias após a colheita.

Experimento 3 (Quadros 4 e 5). A planta foi triturada em uma forrageira, sem peneira, conservada dentro e fora de saco plástico e administrada em diferentes períodos após a colheita $(4,8,12,16,20$, $24,48,72$ e 96 horas). Foram utilizados 33 animais, 17 para a planta 
Quadro 1. Reações ao teste do papel picrosódico das folhas frescas recém colhidas, não trituradas e trituradas, de Manihot glaziovii, e toxicidade em $\mathrm{g} / \mathrm{kg}$ para os caprinos (Experimento 1)

\begin{tabular}{|c|c|c|c|c|}
\hline & \multicolumn{3}{|c|}{$\begin{array}{l}\text { Teste do papel picrosódico: horário } \\
\text { de realização e registro da reação }\end{array}$} & \multirow{3}{*}{$\begin{array}{c}\text { Intensidade } / \\
\text { toxicidade } \\
(\mathrm{g} / \mathrm{kg})\end{array}$} \\
\hline & \multirow[t]{2}{*}{ Início } & \multicolumn{2}{|c|}{ Coloração } & \\
\hline & & Laranja & Vermelho & \\
\hline $\begin{array}{l}\text { Folhas frescas } \\
\text { não trituradas }\end{array}$ & $10: 30$ & $10: 30$ & $10: 32$ & $+++/ 4,3$ \\
\hline $\begin{array}{c}\text { Folhas frescas } \\
\text { triturada }\end{array}$ & $8: 30$ & $8: 30$ & $8: 31$ & $+++/ 12$ \\
\hline
\end{tabular}

Quadro 2. Reações ao teste do papel picrosódico das folhas de Manihot glaziovii não trituradas, conservadas dentro de saco plástico após a sua colheita, e toxicidade em $\mathrm{g} / \mathrm{kg}$ para os caprinos (Experimento 2)

\begin{tabular}{|c|c|c|c|c|}
\hline \multirow{3}{*}{$\begin{array}{l}\text { Tempo } \\
\text { após a } \\
\text { colheita }\end{array}$} & \multicolumn{3}{|c|}{$\begin{array}{l}\text { Teste do papel picrosódico: horário } \\
\text { de realização e registro da reação }\end{array}$} & \multirow{3}{*}{$\begin{array}{c}\text { Intensidade }^{\mathrm{a}} / \\
\text { toxicidade } \\
(\mathrm{g} / \mathrm{kg})\end{array}$} \\
\hline & \multirow[t]{2}{*}{ Início } & \multicolumn{2}{|c|}{ Coloração } & \\
\hline & & Laranja & Vermelho & \\
\hline 4 horas & $14: 30$ & $14: 35$ & $14: 40$ & $+++/ 7,4$ a $12^{\mathrm{b}}$ \\
\hline 8 horas & $16: 10$ & $16: 13$ & $16: 17$ & $+++/ 12$ \\
\hline 12 horas & $8: 07$ & $8: 15$ & $8: 20$ & $+++/ 6,6$ a $12^{\mathrm{b}}$ \\
\hline 16 horas & $7: 15$ & $7: 20$ & $7: 25$ & $+++/ 7,1$ a $12^{b}$ \\
\hline 20 horas & $10: 44$ & $10: 48$ & $10: 53$ & $+++/ 12$ \\
\hline 24 horas & $7: 48$ & $7: 51$ & $7: 54$ & $+++/ 9$ a $12^{b}$ \\
\hline 48 horas & $9: 13$ & $9: 21$ & $9: 30$ & $++/ 12$ \\
\hline 72 horas & $8: 15$ & $8: 20$ & $8: 35$ & $++/ 7,9$ \\
\hline 96 horas & $10: 35$ & $10: 50$ & $12: 30$ & $+/ 6$ \\
\hline 120 horas & $9: 00$ & $9: 05$ & $9: 17$ & $++/ \mathbf{s s}^{\mathrm{c}}$ \\
\hline
\end{tabular}

a +++ Reação acentuada, ++ moderada, + leve, $(+)$ discreta, - sem reação, ss $=$ sem sinais clínicos.

b Resultado diferente entre os animais que consumiram a mesma planta.

c Os dois animais que receberam a planta, não apresentaram sinais clínicos (ss) após ingerir $12 \mathrm{~g} / \mathrm{kg}$.

Quadro 3. Reações ao teste do papel picrosódico das folhas de Manihot glaziovii não trituradas, conservadas fora de saco plástico após a sua colheita, e toxicidade em $\mathrm{g} / \mathrm{kg}$ para os caprinos (Experimento 2)

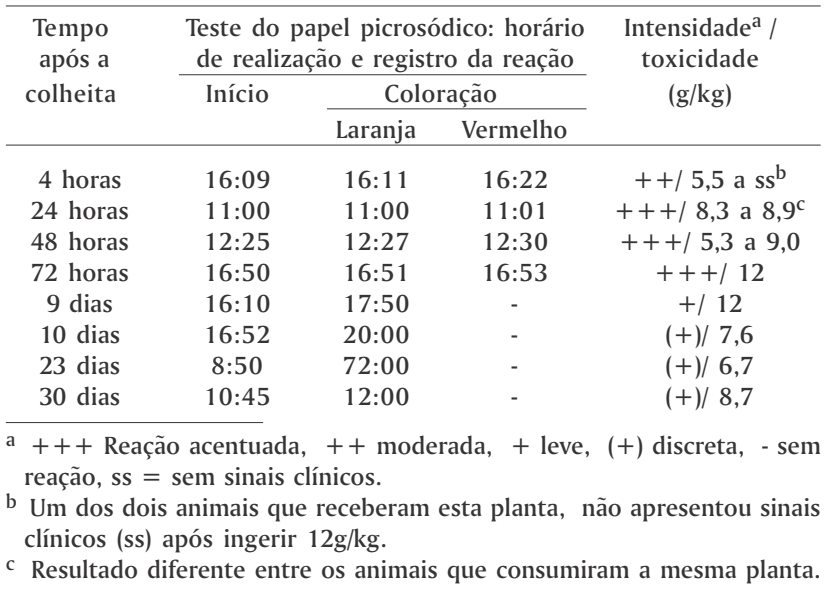

Quadro 4. Reações ao teste do papel picrosódico das folhas de Manihot glaziovii trituradas, conservadas dentro de saco plástico após a sua colheita, e toxicidade em $\mathrm{g} / \mathrm{kg}$ para os caprinos (Experimento 3)

\begin{tabular}{|c|c|c|c|c|}
\hline \multirow{3}{*}{$\begin{array}{l}\text { Tempo } \\
\text { após a } \\
\text { colheita }\end{array}$} & \multicolumn{3}{|c|}{$\begin{array}{l}\text { Teste do papel picrosódico: horário } \\
\text { de realização e registro da reação }\end{array}$} & \multirow{3}{*}{$\begin{array}{c}\text { Intensidade }^{\mathrm{a}} / \\
\text { toxicidade } \\
(\mathrm{g} / \mathrm{kg})\end{array}$} \\
\hline & \multirow[t]{2}{*}{ Início } & \multicolumn{2}{|c|}{ Coloração } & \\
\hline & & Laranja & Vermelho & \\
\hline 4 horas & $11: 30$ & $11: 32$ & $11: 35$ & $+++/ 12$ \\
\hline 8 horas & $8: 16$ & $8: 19$ & $8: 24$ & $+++/ 12$ \\
\hline 12 horas & $8: 31$ & $8: 34$ & $8: 38$ & $+++/ 12$ \\
\hline 16 horas & $7: 45$ & $7: 50$ & $8: 15$ & $++/ 12$ \\
\hline 20 horas & $10: 30$ & $10: 36$ & $10: 40$ & $+++/ 11,6$ a $12^{b}$ \\
\hline 24 horas & $8: 16$ & $8: 19$ & $8: 24$ & $+++/ 12$ \\
\hline 48 horas & $15: 03$ & $15: 10$ & $15: 15$ & $++/ 12$ \\
\hline 72 horas & $17: 05$ & $17: 12$ & $17: 45$ & $++/ 12$ \\
\hline 96 horas & $10: 35$ & $11: 30$ & $12: 00$ & $+/ s s^{c}$ \\
\hline
\end{tabular}

a +++ Reação acentuada, ++ moderada, + leve, (+) discreta, - sem reação, ss $=$ sem sinais clínicos.

b Resultado diferente entre os animais que consumiram a mesma planta. c $\mathrm{O}$ animal que recebeu a planta, não apresentou sinais clínicos (ss) após ingerir $12 \mathrm{~g} / \mathrm{kg}$.

Quadro 5. Reações ao teste do papel picrosódico das folhas de Manihot glaziovii trituradas, conservadas fora de saco plástico após a sua colheita, e toxicidade em g/ kg para os caprinos (Experimento 3)

\begin{tabular}{|c|c|c|c|c|}
\hline \multirow{3}{*}{$\begin{array}{c}\text { Tempo } \\
\text { após a } \\
\text { colheita }\end{array}$} & \multicolumn{3}{|c|}{$\begin{array}{l}\text { Teste do papel picrosódico: horário } \\
\text { de realização e registro da reação }\end{array}$} & \multirow{3}{*}{$\begin{array}{c}\text { Intensidade }^{\mathrm{a}} / \\
\text { toxicidade } \\
(\mathrm{g} / \mathrm{kg})\end{array}$} \\
\hline & \multirow[t]{2}{*}{ Início } & \multicolumn{2}{|c|}{ Coloração } & \\
\hline & & Laranja & Vermelho & \\
\hline 4 horas & $16: 09$ & $16: 09$ & $16: 10$ & $+++/ 12 \mathrm{ss}^{\mathrm{b}}$ \\
\hline 8 horas & $16: 46$ & $16: 47$ & $16: 48$ & $+++/ 12$ \\
\hline 12 horas & $7: 47$ & $7: 58$ & $8: 30$ & $++/ 12 \mathbf{s s}^{\mathrm{c}}$ \\
\hline 16 horas & $11: 22$ & $12: 10$ & $12: 50$ & $+/ 12$ \\
\hline 24 horas & $9: 45$ & $9: 47$ & $9: 50$ & $+++/ \mathbf{s s}^{\mathrm{c}}$ \\
\hline 48 horas & $8: 00$ & $8: 20$ & $8: 35$ & $++/ s s^{c} 12$ \\
\hline 72 horas & $15: 00$ & - & - & $-/ 12$ \\
\hline 96 horas & $8: 00$ & - & - & $-/ s^{d}$ \\
\hline
\end{tabular}

a +++ Reação acentuada, ++ moderada, +leve, (+) discreta, - sem reação, ss $=$ sem sinais clínicos.

b Dois dos três animais que receberam esta planta, não apresentaram sinais clínicos (ss) após ingerir $12 \mathrm{~g} / \mathrm{kg}$.

c Um dos dois animais que receberam esta planta, não apresentou sinais clínicos (ss) após ingerir $12 \mathrm{~g} / \mathrm{kg}$.

${ }^{\mathrm{d}}$ Os dois animais que receberam esta planta, não apresentaram sinais clínicos (ss) após ingerir $12 \mathrm{~g} / \mathrm{kg}$.

conservada dentro do saco plástico e 16 animais para a planta conservada fora do saco plástico.

Nos Experimentos 2 e 3 foram utilizados um ou dois caprinos por cada período de administração. Foram utilizados 40 caprinos como controle, dois no Experimento 1, e um por cada período de administração após a colheita e tipo de conservação da planta nos Experimentos 2 e 3 . Nos animais controle também foram avaliados a temperatura e as frequiências cardíaca e respiratória.

\section{RESULTADOS}

As amostras de Manihot glaziovii apresentaram toxicidade semelhante nas diferentes épocas em que foram testadas. Esse perío- 
Quadro 6. Experimento em caprinos com as folhas recém colhidas, não trituradas e trituradas, de Manihot glaziovii, na dosagem de 12g/kg (Experimento 1)

\begin{tabular}{cccccccc}
\hline $\begin{array}{c}\text { Caprino } \\
\text { no. }\end{array}$ & Folhas & $\begin{array}{c}\text { Data da } \\
\text { coleta } \\
\text { (Peso) }\end{array}$ & $\begin{array}{c}\text { Dose } \\
(\mathrm{g} / \mathrm{kg})\end{array}$ & $\begin{array}{c}\text { Início / fim da } \\
\text { administração } \\
\text { (Horário) }\end{array}$ & $\begin{array}{c}\text { Início dos } \\
\text { sintomas } \\
\text { (Horário) }\end{array}$ & $\begin{array}{c}\text { Administração } \\
\text { do tiossulfato de } \\
\text { sódio (Horário) }\end{array}$ & $\begin{array}{c}\text { Recuperação } \\
\text { (Horário) }\end{array}$ \\
\hline $35(12,2 \mathrm{~kg})$ & Não triturada & 23.01 .04 & 7,4 & $10: 30 / 11: 00$ & $11: 00$ & $11: 20$ & $11: 35$ \\
$61(10,4 \mathrm{~kg})$ & Não triturada & 23.01 .04 & 5,7 & $10: 30 / 12: 00$ & $12: 10$ & $12: 25$ & $12: 35$ \\
$57(11,9 \mathrm{~kg})$ & Não triturada & 27.01 .04 & 12 & $8: 35 / 9: 25$ & $9: 35$ & $10: 02$ & $10: 15$ \\
$46(12,7 \mathrm{~kg})$ & Não triturada & 27.01 .04 & 12 & $8: 35 / 9: 02$ & $9: 10$ & $9: 50$ & $10: 05$ \\
$06(21,5 \mathrm{~kg})$ & Triturada & 04.02 .04 & 12 & $8: 20 / 8: 45$ & $9: 20$ & $9: 50$ & $10: 02$ \\
$27(20,8 \mathrm{~kg})$ & Triturada & 04.02 .04 & 12 & $8: 45 / 9: 30$ & $9: 55$ & $10: 40$ & $10: 55$
\end{tabular}

Quadro 7. Experimento em caprinos com as folhas de Manihot glaziovii não trituradas e conservadas dentro de saco plástico, na dosagem de 12g/kg (Experimento 2)

\begin{tabular}{|c|c|c|c|c|c|c|c|}
\hline $\begin{array}{l}\text { Caprino } \\
\text { no. } \\
\text { (Peso) }\end{array}$ & $\begin{array}{c}\text { Data do } \\
\text { experimento }\end{array}$ & $\begin{array}{c}\text { Período de } \\
\text { intoxicação } \\
\text { após a colheita }\end{array}$ & $\begin{array}{l}\text { Dose } \\
\mathrm{g} / \mathrm{kg}\end{array}$ & $\begin{array}{l}\text { Início / fim da } \\
\text { administração } \\
\text { (Horário) }\end{array}$ & $\begin{array}{l}\text { Início dos } \\
\text { sintomas } \\
\text { (Horário) }\end{array}$ & $\begin{array}{l}\text { Administração } \\
\text { do tiossulfato de } \\
\text { sódio (Horário) }\end{array}$ & $\begin{array}{l}\text { Recuperação } \\
\text { (Horário) }\end{array}$ \\
\hline $51(9,7 \mathrm{~kg})$ & 23.01 .04 & 4 horas & 7,4 & $15: 00 / 16: 27$ & $3: 55$ & $16: 30$ & $16: 36$ \\
\hline $59(11 \mathrm{~kg})$ & 23.01 .04 & 4horas & 12 & $15: 00 / 15: 30$ & $15: 30$ & $15: 40$ & $15: 45$ \\
\hline 38 (11 kg) & 23.01 .04 & 8 horas & 12 & $17: 12 / 18: 15$ & $18: 15$ & $18: 34$ & $18: 37$ \\
\hline 56 (11 kg) & 23.01 .04 & 8 horas & 12 & $17: 12 / 17: 40$ & $17: 50$ & 18:02 & $\begin{array}{c}\text { 18:08 (morreu } \\
\text { no dia seguinte) }\end{array}$ \\
\hline $\mathrm{s} / \mathrm{n}(9,2 \mathrm{~kg})$ & 27.01 .04 & 12 horas & 6,6 & $18: 15$ / 19:10 & 19:00 & $19: 25$ & $19: 32$ \\
\hline $39(11,4 \mathrm{~kg})$ & 27.01 .04 & 12 horas & 12 & $18: 05 / 19>35$ & $19: 50$ & $20: 48$ & $21: 00$ \\
\hline 37 (11,5kg) & 30.01 .04 & 16 horas & 12 & 8:05 / 8:50 & $9: 00$ & $9: 45$ & $9: 53$ \\
\hline $43(8,9 \mathrm{~kg})$ & 30.01 .04 & 16 horas & 7,1 & $8: 05$ / 8:45 & $8: 45$ & $10: 30$ & $10: 3$ \\
\hline 32 (14,4kg) & 30.01 .04 & 20 horas & 12 & $10: 57 / 11: 15$ & $11: 50$ & 12:05 & $12: 12$ \\
\hline 97 (13,8kg) & 30.01 .04 & 20 horas & 12 & $10: 57$ / 11:43 & $12: 00$ & $12: 40$ & $12: 43$ \\
\hline $54(10,8 \mathrm{~kg})$ & 24.01 .04 & 24 horas & 9 & $9: 30 / 10: 40$ & $10: 40$ & $10: 55$ & $11: 00$ \\
\hline $58(12,2 \mathrm{~kg})$ & 24.01 .04 & 24 horas & 12 & $9: 30 / 10: 00$ & $9: 55$ & $10: 30$ & $10: 35$ \\
\hline $51(11,2 \mathrm{~kg})$ & 11.03 .04 & 48 horas & 12 & $8: 50$ / 9:30 & 10:00 & $10: 25$ & $10: 33$ \\
\hline $58(13,7 \mathrm{~kg})$ & 11.03 .04 & 48 horas & 12 & $8: 50$ / 9:15 & $10: 20$ & $10: 38$ & $10: 45$ \\
\hline $54(12,7 \mathrm{~kg})$ & 12.03 .04 & 72 horas & 7,9 & $8: 15$ / 9:20 & $9: 20$ & $9: 40$ & $9: 45$ \\
\hline $40(13,9 \mathrm{~kg})$ & 03.04 .04 & 96 horas & 6 & $9: 11 / 10: 00$ & $10: 00$ & $10: 15$ & $10: 20$ \\
\hline $\mathrm{s} / \mathrm{n} \quad(9,5 \mathrm{~kg})$ & 04.04 .04 & 120 horas & 12 & $9: 20 / 11: 15$ & $s s^{\mathrm{a}}$ & 13:05 & $s s^{\mathrm{a}}$ \\
\hline 01 (9,0kg) & 04.04 .04 & 120 horas & 12 & $9: 20 / 11: 00$ & Ss & $13: 05$ & ss \\
\hline
\end{tabular}

do se estendeu desde o início do período das chuvas (janeiro) até o final do mesmo (junho) (Quadros 6, 7, 8. 9 e 10). Não foi detectada interferência nos resultados dos experimentos com o fato de ter empregado os mesmos caprinos experimentais em mais de uma ocasião, já que a ocorrência da intoxicação foi independente do fato do animal ter sido intoxicado anteriormente (Quadros 6, 7, 8. 9 e 10).

Os resultados do teste do papel picrosódico associados à toxicidade da planta são mostrados nos Quadros 1, 2, 3, 4 e 5 . Os resultados do Experimento 1 são apresentados no Quadro 6. As amostras da planta não triturada possuem toxicidade igual ou maior do que as amostras da planta triturada, uma vez que, em dois dos quatro animais utilizados para testar a planta não triturada a dose tóxica foi de 5,7 e 7,4 g/ $\mathrm{kg}$, enquanto que nos dois restantes e nos dois que receberam a planta triturada a dose tóxica foi de $12 \mathrm{~g} / \mathrm{kg}$. Além da maior toxicidade para dois animais, os animais que ingeriram a planta não triturada apresentaram sinais clínicos em menor tempo do que os animais que consumiram a planta triturada, embora ambos apresentassem sinais clínicos evidentes de uma intoxicação cianídrica.

Os resultados do Experimento 2 são apresentados nos Qua- dros 7 e 8 . A planta não triturada e conservada fora de saco plástico apresentou a menor dose tóxica, que foi $5,3 \mathrm{~g} / \mathrm{kg}$ após 48 horas de colhida e permaneceu tóxica durante todo o período experimental, que foi de 30 dias (Quadro 7). As amostras conservadas dentro de saco plástico apresentaram a maior toxicidade após 96 horas de colhida $(6 \mathrm{~g} / \mathrm{kg})$ e mantiveram toxicidade até as 96 horas após a colheita (Quadro 8).

Os resultados do Experimento 3 são apresentados nos Quadros 9 e 10. A planta triturada, conservada dentro e fora de saco plástico, apresentou toxicidade semelhante e o período após a colheita em que permaneceu tóxica foi de 72 horas para os dois tipos de conservação.

Em todos os experimentos, independente do processamento da planta (não triturada e triturada) e do tipo de conservação, os sinais clínicos foram semelhantes, caracterizados inicialmente por dificuldade de deglutição e por dispnéia (Fig. 2), seguido de mucosas cianóticas, ereção das orelhas, incoordenação, tremores musculares, nistagmo, e tremor de cabeça e das pálpebras, seguidos de queda e permanência em decúbito lateral com movimentos de pedalagem e opistótono. $O$ tempo de administração da planta variou de 20 a 80 minutos e na maioria dos casos 


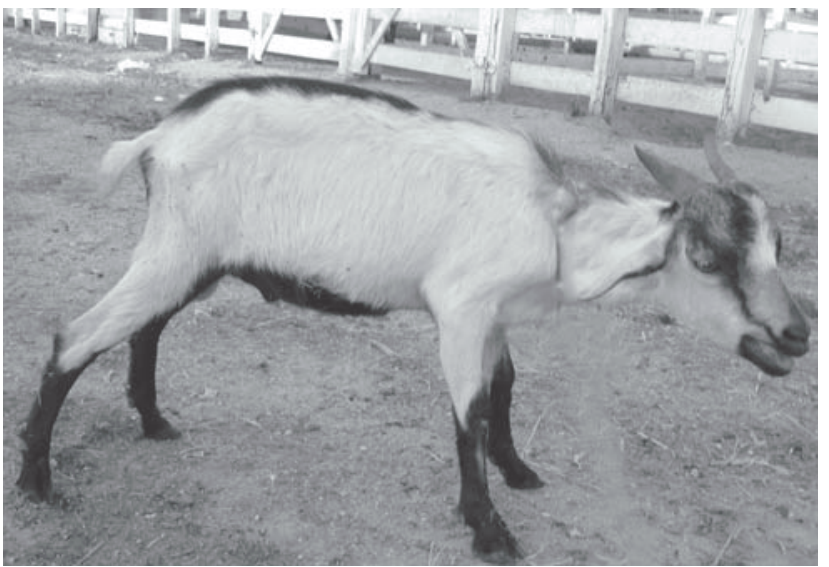

Fig. 2. Marcada dificuldade respiratória e membros abertos de caprino intoxicado experimentalmente por Manihot glaziovii. o aparecimento dos sinais clínicos ocorreu durante a administração ou até 5 a 10 minutos após o final da mesma. Em todos os animais que apresentaram sinais, a duração dos sinais clínicos até o tratamento foi de 10 minutos a 1 hora (Quadros 6, 7, 8.9 e $10)$.

Logo após a queda seguida de decúbito lateral e opistótono, os animais foram tratados apresentando recuperação após 2 a 30 minutos após a administração (Quadros 6, 7, 8, 9 e 10). Os animais eram considerados como recuperados quando conseguiam se levantar e andar normalmente. Um animal que consumiu a planta não triturada conservada dentro do saco plástico foi encontrado morto (Exp. 2, Quadro 7, Caprino 56), no dia seguinte após o experimento com a planta 8 horas após a sua colheita. Este animal apresentou durante o experimento sinais clínicos de uma intoxicação cianídrica. Na necropsia foi observado herniação cerebelar através do forâmen magno, presença da planta não digerida no rúmen, bexiga repleta de urina, con-

Quadro 8. Experimento em caprinos com as folhas de Manihot glaziovii não trituradas e conservadas fora de saco plástico, na dosagem de $12 \mathrm{~g} / \mathrm{kg}$ (Experimento 2)

\begin{tabular}{|c|c|c|c|c|c|c|c|}
\hline $\begin{array}{l}\text { Caprino } \\
\text { no. } \\
\text { (Peso) }\end{array}$ & $\begin{array}{c}\text { Data do } \\
\text { experimento }\end{array}$ & $\begin{array}{c}\text { Período de } \\
\text { intoxicação } \\
\text { após a colheita }\end{array}$ & $\begin{array}{l}\text { Dose } \\
\mathrm{g} / \mathrm{kg}\end{array}$ & $\begin{array}{c}\text { Início / fim da } \\
\text { administração } \\
\text { (Horário) }\end{array}$ & $\begin{array}{l}\text { Início dos } \\
\text { sintomas } \\
\text { (Horário) }\end{array}$ & $\begin{array}{l}\text { Administração } \\
\text { do tiossulfato de } \\
\text { sódio (Horário) }\end{array}$ & $\begin{array}{c}\text { Recuperação } \\
\text { (Horário) }\end{array}$ \\
\hline $\mathrm{s} / \mathrm{n}(11,1 \mathrm{~kg})$ & 07.04 .04 & 4 horas & 5,5 & 4:00 / 5:00 & $4: 40$ & $5: 12$ & $5: 22$ \\
\hline $67(12,3 \mathrm{~kg})$ & 07.04 .04 & 4 horas & 12 & 4:10 / 5:00 & $\mathbf{S s}^{\mathrm{a}}$ & $6: 00$ & \\
\hline 44 (9,7kg) & 08.04 .04 & 24 horas & 8,3 & $11: 45 / 12: 45$ & $12: 40$ & $12: 55$ & $13: 00$ \\
\hline $52(10,4 \mathrm{~kg})$ & 08.04 .04 & 24 horas & 8,9 & $11: 15 / 12: 10$ & $12: 10$ & $12: 25$ & $12: 35$ \\
\hline $35(17,2 \mathrm{~kg})$ & 09.04 .04 & 48 horas & 9 & $9: 15$ / 11:20 & $11: 20$ & $11: 33$ & $11: 43$ \\
\hline $67(12,3 \mathrm{~kg})$ & 09.04 .04 & 48 horas & 5,3 & $9: 30 / 11: 00$ & $11: 00$ & $11: 15$ & $11: 35$ \\
\hline $11(8,8 \mathrm{~kg})$ & 16.04 .04 & 72 horas & 12 & $10: 25 / 11: 30$ & $11: 55^{b}$ & $12: 30$ & $12: 35$ \\
\hline 50 (8,5kg) & 16.04 .04 & 72 horas & 12 & $10: 25 / 11: 00$ & $11: 45^{\mathrm{b}}$ & $12: 00$ & $12: 05$ \\
\hline $\mathrm{s} / \mathrm{n}(12,5 \mathrm{~kg})$ & 08.06 .04 & 9 dias & 5,6 & $16: 10 / 17: 10$ & 15:09 & $17: 20$ & $17: 24$ \\
\hline $52(11,5 \mathrm{~kg})$ & 08.06 .04 & 9 dias & 12 & $16: 10 / 17: 10$ & $17: 00$ & $17: 40$ & $17: 50$ \\
\hline $51(11,5 \mathrm{~kg})$ & 09.06 .04 & 10 dias & 7,6 & $15: 08 / 16: 10$ & $16: 00$ & $16: 35$ & $16: 45$ \\
\hline 54 (15kg) & 11.06 .04 & 23 dias & 6,7 & $8: 48$ / 9:45 & $9: 50$ & $10: 05$ & $10: 07$ \\
\hline 02 (15kg) & 18.06 .04 & 30 dias & 8,7 & $8: 25$ / 9:50 & $9: 50$ & $11: 00$ & $11: 20$ \\
\hline
\end{tabular}

$\overline{\mathrm{a}}$ ss $=$ Sem sintomas, ${ }^{\mathrm{b}}$ intoxicação leve.

Quadro 9. Experimento em caprinos com as folhas de M. glaziovii trituradas e conservadas dentro de saco plástico na dosagem de $12 \mathrm{~g} / \mathrm{kg}$ (Experimento 3)

\begin{tabular}{|c|c|c|c|c|c|c|c|}
\hline $\begin{array}{l}\text { Caprino } \\
\text { no. } \\
\text { (Peso) }\end{array}$ & $\begin{array}{c}\text { Data do } \\
\text { experimento }\end{array}$ & $\begin{array}{c}\text { Período de } \\
\text { intoxicação } \\
\text { após a colheita }\end{array}$ & $\begin{array}{l}\text { Dose } \\
\mathrm{g} / \mathrm{kg}\end{array}$ & $\begin{array}{l}\text { Início / fim da } \\
\text { administração } \\
\text { (Horário) }\end{array}$ & $\begin{array}{l}\text { Início dos } \\
\text { sintomas } \\
\text { (Horário) }\end{array}$ & $\begin{array}{l}\text { Administração } \\
\text { do tiossulfato de } \\
\text { sódio (Horário) }\end{array}$ & $\begin{array}{c}\text { Recuperação } \\
\text { (Horário) }\end{array}$ \\
\hline 03 (23kg) & 04.02 .04 & 4 horas & 12 & $11: 15 / 12: 00$ & $12: 16$ & $13: 20$ & $13: 30$ \\
\hline 04 (26kg) & 04.02 .04 & 4 horas & 12 & $11: 15 / 11: 40$ & $11: 44$ & $12: 14$ & $12: 20$ \\
\hline $05^{\mathrm{b}}(27 \mathrm{~kg})$ & 04.02 .04 & 8 horas & 12 & $16: 00 / 17: 00$ & $18: 05$ & 19:00 & 19:05 \\
\hline $20^{\mathrm{b}}(26 \mathrm{~kg})$ & 04.02 .04 & 8 horas & 12 & $16: 00 / 17: 23$ & 18:05 & 19:00 & 19:05 \\
\hline $21(23,5 \mathrm{~kg})$ & 19.02 .04 & 12 horas & 12 & $8: 30$ / 8:43 & $9: 10$ & $9: 28$ & $9: 33$ \\
\hline $30(20,1 \mathrm{~kg})$ & 19.02 .04 & 12 horas & 12 & $8: 30 / 8: 50$ & $9: 52$ & $10: 23$ & $10: 40$ \\
\hline $24(19,5 \mathrm{~kg})$ & 06.02 .04 & 16 horas & 12 & $8: 10 / 8: 40$ & $8: 40$ & $8: 50$ & $8: 55$ \\
\hline $29(18,5 \mathrm{~kg})$ & 06.02 .04 & 16 horas & 12 & $8: 10$ / 8:50 & $8: 30$ & $9: 05$ & $9: 07$ \\
\hline $34(13,5 \mathrm{~kg})$ & 06.02 .04 & 20 horas & 11,6 & $10: 41 / 11: 16$ & $11: 20$ & $11: 44$ & $11: 50$ \\
\hline 55 (10kg) & 06.02 .04 & 20 horas & 12 & $10: 41 / 11: 08$ & $11: 17$ & $11: 30$ & $11: 44$ \\
\hline 33 (12,6kg) & 05.04 .04 & 24 horas & 12 & $8: 40$ / 8:55 & $9: 30$ & $9: 50$ & 10:05 \\
\hline $36(14,6 \mathrm{~kg})$ & 05.04 .04 & 24 horas & 12 & $8: 40$ / 9:02 & $9: 16$ & $9: 25$ & $9: 30$ \\
\hline $07(9,5 \mathrm{~kg})$ & 01.04 .04 & 48 horas & 12 & $15: 00 / 15: 45$ & $15: 50^{b}$ & $17: 00$ & $17: 05$ \\
\hline 08b (9kg) & 01.04 .04 & 48 horas & 12 & $15: 00 / 15: 20$ & $16: 00$ & $17: 00$ & 17:05 \\
\hline $51(11 \mathrm{~kg})$ & 02.04 .04 & 72 horas & 12 & $15: 05 / 15: 45$ & $15: 50^{\mathrm{b}}$ & $17: 00$ & $17: 05$ \\
\hline $54(12,9 \mathrm{~kg})$ & 02.04 .04 & 72 horas & 12 & $15: 05 / 16: 00$ & $4: 10$ & 17:00 & 17:05 \\
\hline $38(14,1 \mathrm{~kg})$ & 03.04 .04 & 96 horas & 12 & $9: 11$ / 9:45 & $\mathbf{s s}^{\mathrm{a}}$ & $10: 45$ & SS \\
\hline
\end{tabular}

${ }^{\mathrm{a} s \mathrm{~s}}=$ Sem sintomas, ${ }^{\mathrm{b}}$ animal com sinais clínicos leves. 
Quadro 10. Experimento em caprinos com as folhas de Manihot glaziovii trituradas e conservadas fora de saco plástico, na dosagem de $12 \mathrm{~g} / \mathrm{kg}$ (Experimento 3)

\begin{tabular}{|c|c|c|c|c|c|c|c|}
\hline $\begin{array}{c}\text { Caprino } \\
\text { no. } \\
\text { (Peso) }\end{array}$ & $\begin{array}{c}\text { Data do } \\
\text { experimento }\end{array}$ & $\begin{array}{l}\text { Período de } \\
\text { intoxicação } \\
\text { após a colheita }\end{array}$ & $\begin{array}{l}\text { Dose } \\
\mathrm{g} / \mathrm{kg}\end{array}$ & $\begin{array}{l}\text { Início / fim da } \\
\text { administração } \\
\text { (Horário) }\end{array}$ & $\begin{array}{l}\text { Início dos } \\
\text { sintomas } \\
\text { (Horário) }\end{array}$ & $\begin{array}{l}\text { Administração } \\
\text { do tiossulfato de } \\
\text { sódio (Horário) }\end{array}$ & $\begin{array}{c}\text { Recuperação } \\
\text { (Horário) }\end{array}$ \\
\hline $67(12,3 \mathrm{~kg})$ & 05.04 .04 & 4 horas & 12 & $16: 00 / 17: 00$ & $\mathbf{s s}^{\mathrm{a}}$ & 18:00 & $\mathbf{s s}^{\mathrm{a}}$ \\
\hline $44(9,7 \mathrm{~kg})$ & 09.04 .04 & 4 horas & 12 & $14: 30 / 15: 00$ & sS & $16: 00$ & ss \\
\hline 09 (11kg) & 09.04 .04 & 4 horas & 12 & $14: 30 / 15: 10$ & $3: 30$ & $4: 00$ & $4: 06$ \\
\hline 35 (12,3kg) & 16.04 .04 & 8 horas & 12 & $16: 35 / 17: 10$ & $17: 20$ & $17: 45$ & $17: 47$ \\
\hline $52(10,4 \mathrm{~kg})$ & 16.04 .04 & 8 horas & 12 & $16: 05 / 16: 45$ & $17: 20$ & $17: 45$ & $17: 53$ \\
\hline $44(9,7 \mathrm{~kg})$ & 23.04 .04 & 12 horas & 12 & $8: 05$ / 8:45 & ss & $10: 30$ & ss \\
\hline $52(10,4 \mathrm{~kg})$ & 23.04 .04 & 12 horas & 12 & $8: 05$ / 9:00 & $10: 00$ & $10: 35$ & $10: 37$ \\
\hline 44 (9,7kg) & 11.05 .04 & 16 horas & 12 & $8: 20$ / 8:48 & $10: 10$ & $10: 35$ & $10: 45$ \\
\hline 67 (12,3kg) & 14.04 .04 & 24 horas & 12 & 9:00 / 9:35 & ss & $11: 00$ & ss \\
\hline $10(10,4 \mathrm{~kg})$ & 11.05 .04 & 24 horas & 12 & $15: 48 / 16: 15$ & ss & 18:00 & ss \\
\hline 38 (13,8kg) & 12.05 .04 & 48 horas & 12 & $7: 50$ / 8:35 & ss & $10: 30$ & ss \\
\hline $40(13,2 \mathrm{~kg})$ & 12.05 .04 & 48 horas & 12 & $7: 50$ / 8:50 & ss & $10: 30$ & ss \\
\hline $11(10,7 \mathrm{~kg})$ & 13.04 .04 & 48 horas & 12 & $14: 40 / 15: 10$ & $15: 08$ & $16: 00$ & $16: 15$ \\
\hline $51(10,1 \mathrm{~kg})$ & 14.04 .04 & 72 horas & 12 & $15: 00 / 15: 40$ & $15: 35$ & $16: 15$ & $16: 55$ \\
\hline $44(9,5 \mathrm{~kg})$ & 25.05 .04 & 96 horas & 12 & $8: 10$ / 9:15 & ss & $11: 32$ & ss \\
\hline 52 (10kg) & 25.05 .04 & 96 horas & 12 & $8: 10 / 10: 00$ & ss & $11: 32$ & $s s^{\mathrm{a}}$ \\
\hline
\end{tabular}

gestão dos rins e edema pulmonar nos lóbulos craniais; também foi observado edema na porção caudal da traquéia. Os demais órgãos não apresentaram lesões de significado. Na histopatologia não se observaram alterações significantes. Em todos os experimentos, os animais apresentaram aumento de temperatura e das freqüiências cardíaca e respiratória. Após o tratamento, as mesmas eram normalizadas.

\section{DISCUSSÃO E CONCLUSÕES}

Os resultados deste trabalho demonstram que Manihot glaziovii apresenta toxicidade durante todo o seu ciclo vegetativo, que se estende por todo período de chuvas; portanto, as intoxicações podem ocorrer em qualquer época em que se encontra a planta, independente da sua fase de crescimento. Outras plantas cianogênicas como Sorghum spp são tóxicas somente na fase de crescimento, quando estão rebrotando (Mendez 1993). Por outro lado, Prunus sellowii, que também é cianogênica, não apresenta diferenças de toxicidade entre as diferentes fases do seu ciclo vegetativo (Gava et al 1992).

Segundo Canella et al. (1968) a intoxicação por Manihot spp ocorre quando as primeiras chuvas são seguidas de uma estiagem de vários dias e os animais ingerem as plantas murcha e seca. No avançar da estação chuvosa Manihot glaziovii continua tóxica, no entanto não é mais perigosa porque os animais encontrando forragem abundante, não mais a comem ou o fazem em quantidades insuficientes para causar a morte. Segundo fazendeiros a intoxicação só ocorre quando a planta está brotando no início da estação das chuvas ou quando os animais ingerem a planta murcha. A informação sobre a ocorrência da intoxicação com a planta murcha pareceria não ser verdadeira, já que no presente trabalho a planta apresentou toxicidade semelhante nos diferentes períodos após a colheita. Essa crença poderia ser devida a dois fatos: o primeiro é que após o corte o animal tem acesso a partes das plantas que normalmente não pode atingir; o segundo é que aparentemente, muitas plantas são mais palatáveis quando murchas, o que favorece a sua ingestão em quantidades tóxicas. Em outras plantas cianogênicas como Anadenanthera colubrina (Piptadenia macrocarpa), Piptadenia viridiflora e Holocalyx glaziovii não se observam diferenças na toxicidade em relação à planta recém colhida ou murcha (Tokarnia et al. 1994, 1999).

Com relação ao Experimento 1, tanto as amostras trituradas quanto as não trituradas resultaram tóxicas, sugerindo a impossibilidade de administrar a planta imediatamente após a colheita, independente do tipo de processamento a que esta seja submetida. Nos experimentos 2 e 3 observou-se que a Manihot glaziovii continua tóxica vários dias após a colheita estando muitas vezes murcha e seca. Por outro lado, trabalhos anteriores com $M$. glaziovii não produziram toxidez após o processo de dessecagem (Tokarnia et al. 1999), ao contrário do que se observou com outras plantas cianogênicas como Anadenanthera colubrina, Piptadenia viridiflora e Holocalyx glaziovii que em experimentos com bovinos (Tokarnia et al. 1994, 1999) e coelhos (Brito et al. 2000) mantiveram sua toxidez por períodos de 2 a 5 meses após a secagem. Esses resultados alertam para a possibilidade de que o feno ou a silagem de Manihot glaziovii permaneçam tóxicas por algum período após a sua preparação. Segundo Aplin (1976) as plantas cianogênicas perdem o $\mathrm{HCN}$ quando cortadas, dessecadas ou quando submetidas ao processo de volatilização, portanto o feno preparado a partir de uma plantação potencialmente perigosa será, quando bem seco, seguro para a alimentação de animais. No entanto, Kingsbury (1964) considera que o feno fresco preparado a partir de algumas plantas, pode ser perigoso, porém com o passar do tempo não haveria maiores riscos, provavelmente pela volatização do HCN. Van der Walt (1944) informa que a quantidade de HCN liberada por Andropogon sorghum é menor quando o processo de dessecagem é rápido. Sudan grass dessecado em forno perde um pouco de $\mathrm{HCN}$, porém mais $\mathrm{HCN}$ é perdido quando esse processo é feito ao sol. Quando dessecado à sombra o HCN é todo ou quase totalmente eliminado. Para 
Radostits et al. (2000) a secagem, fenação e fatores físicos, como resfriamento e congelamento, podem reduzir a toxicidade dos materiais cianogênicos por meio da destruição da $\beta$-glicosidase, mas o material vegetal permanece potencialmente tóxico, requerendo somente a enzima de microorganismos da flora ruminal, para se tornar novamente tóxico.

Quanto ao tipo de conservação observou-se que a planta não triturada mantida ao meio ambiente (Exp. 2, Quadro 3) permanece tóxica por mais tempo (pelo menos 30 dias) do que a planta triturada (Exp. 3, Quadro 5) que manteve sua toxicidade até 72 horas, independente do fato de ter sido conservada ao meio ambiente ou em saco plástico (Quadros 2 e 4). Esses resultados sugerem que a planta deve ser triturada, guardada fora de sacos plásticos, e somente 96 horas deste procedimento deve ser administrada aos animais. A mesma recomendação deve ser feita em relação ao feno, que deve ser preparado com a planta triturada. A conservação em saco plástico e possivelmente a silagem favorecem a eliminação do ácido cianídrico. Isso ocorre, provavelmente, por que a planta dentro do saco perde menos água do que fora do mesmo, uma vez que o $\mathrm{HCN}$ é um produto que se volatiliza rapidamente após o desdobramento (hidrólise) dos glicosídeos cianogênicos, que ocorre com maior facilidade em presença de água (Araújo et al. 2001, Cereda 2003).

No que diz respeito aos sinais clínicos, estes se iniciam com incapacidade de deglutição associada à dispnéia, seguidos de uma insuficiência respiratória aguda em consequiência da anóxia, que se apresenta com sinais nervosos (incoordenação, tremores musculares, nistágmo, opistótono). Esses sinais devem-se à interação do HCN no processo enzimático final (citocromooxidase) da respiração aeróbia mitocondrial, envolvendo os mecanismos de transporte de elétrons (Smith 1994). A partir desta perspectiva bioquímica, o $\mathrm{HCN}$ interage com esses sistemas enzimáticos através de seu cofator associado, o íon Férrico $\left(\mathrm{Fe}^{3}\right)$. Em decorrência, o oxigênio ligado á hemoglobina no compartimento intravascular fica, de forma efetiva, inibido em sua utilização nas vias intravasculares de respiração oxidativa. $\mathrm{O}$ uso diminuído do oxigênio resulta em hipóxia celular e redução na geração de ATP, para os processos dependentes de energia, o que também estimula o aumento no esforço respiratório pulmonar. Isto resulta numa alteração da coloração de sangue (fica com tom vermelho mais rutilante), em decorrência da hiperoxigenação e redução do uso de oxigênio $\left(\mathrm{O}_{2}\right)$ pelas células (Smith 1994).

O tratamento aplicado nos animais intoxicados, na dosagem de $50 \mathrm{ml} / 100 / \mathrm{kg} / \mathrm{pv}$ de uma solução de tiossulfato de sódio a $20 \%$ foi sempre eficiente, promovendo a imediata recuperação dos animais. Trabalhos semelhantes a este, obtiveram também resultados positivos quanto ao tratamento de caprinos (Soto-Blanco et al. 2004) e bovinos (Gava et al. 1992, Tokarnia et al. 2000) intoxicados experimentalmente por plantas cianogênicas. A intoxicação por HCN é uma das raras intoxicações que podem ser tratadas de modo específico e efetivo e é recomendada a administração endovenosa de tiossulfato de sódio na dosagem de $600 \mathrm{mg} / \mathrm{kg}$ em solução a $20 \%$, o que significa $3,3 \mathrm{ml} / \mathrm{kg}$ da solução a $20 \%$, o que equivale a $330 \mathrm{ml} / 100 \mathrm{~kg}$ (Tokarnia et al. 2000). Há muitos anos o tratamento tradicional era feito pela aplicação endovenosa de uma mistura de nitrito de sódio e tiossulfato de sódio, dissolvendo $5 \mathrm{~g}$ de nitrito de sódio e $15 \mathrm{~g}$ de tiossulfato de sódio em $200 \mathrm{ml}$ de água destilada e aplicado lentamente na dosagem de $40 \mathrm{ml}$ para cada $50 \mathrm{~kg}$ (Tokarnia et al. 2000). Porém não se utiliza mais, por causar intoxicação por nitrato e nitrito quando administrado em excesso, uma vez que o nitrito induz a formação de metemoglobina, comprometendo o transporte de $\mathrm{O}_{2}$ pela hemoglobina para os tecidos, assim ocorrendo uma anóxia anêmica e exacerbando a anóxia tissular (Kingsbury 1964, Alvariza 1993, Smith 1994, Radostits et al. 2000).

Em relação aos resultados da prova do papel picrosódico, podemos concluir que o teste tem valor apenas relativo na avaliação das concentrações de glicosídeos cianogênicos em material vegetal, visto que em muitos casos à medida que se passava o tempo de colheita da planta, a mesma não reagia ao teste do papel picrosódico ou apresentava reação leve ou discreta, no entanto, em alguns casos, manteve a toxicidade quando foi administrada aos caprinos (Quadros 3 e 5). Resultados semelhantes foram observados por Tokarnia et al. (1999), quando folhas dessecadas da Anadenanthera colubrina (Piptadenia macrocarpa) $e$ Piptadenia viridiflora umedecidas reagiram lentamente ao teste do papel picrosódico, porém foram capazes de induzir a intoxicação letal. Por outro lado, amostras frescas de Manihot glaziovii e Holocalyx glaziovii reagiram ao teste de papel picrosódico sempre muito rápido (5 minutos), no entanto, a intoxicação por Manihot glaziovii não foi reproduzida com essas amostras positivas (Tokarnia et al. 1999).

A variação nessas reações pode ser atribuída a diversos fatores. Everist (1974) menciona que certos glicosídeos se desintegram com facilidade, enquanto outros se mantém estáveis. Em algumas plantas a liberação do HCN é mais rápido que em outras, seja pela natureza dos próprios glicosídeos ou pelo tipo e quantidade de enzimas disponíveis para hidrólise. Também deve ser lembrado que os glicosídeos cianogênicos são solúveis em água, liberando mais ácido cianídrico quando misturados com a mesma (Cereda 2003). Provavelmente este pode ser um fator importante para aquelas amostras que não reagiram ao teste do papel picrosódico, já que as mesmas estavam em processo de secagem, ou seja, com pouca água.

Neste trabalho as doses tóxicas de M. glaziovii para caprinos, de 5,3 a $12 \mathrm{~g} / \mathrm{kg}$, foram semelhantes às doses tóxicas para bovinos que são, também, de 5 a 12 g/kg pv (Tokarnia et al. 1999, Amorim et al. 2004). Na região Nordeste existem numerosos históricos da ocorrência de intoxicação por Manihot spp em bovinos e caprinos, no entanto, os produtores afirmam que não ocorre intoxicação em ovinos. Segundo Radostits et al (2000) os ovinos são mais resistentes que os bovinos, aparentemente por causa de diferenças entre os sistemas enzimáticos nos compartimentos anteriores do estômago de tais animais. Outra possibilidade para a aparente menor frequiência da intoxicação em ovinos é o seu diferente hábito de pastejo, já que esta espécie não consome plantas arbustivas ou arbóreas na mesma quantidade que os caprinos e bovinos.

Como Manihot spp são forrageiras frequentemente utilizadas na região Nordeste, além dos riscos de intoxicação aguda há riscos da ocorrência de intoxicações crônicas, que poderiam ocorrer em conseqüência da ingestão continuada de doses menores que as necessárias para causar intoxicação aguda. Vários 
trabalhos foram realizados para comprovar o efeito tóxico dos glicosídeos cianogênicos por ingestão por longos períodos, sendo demonstrado que são capazes de causar lesões no sistema nervoso central caracterizadas por gliose, espongiose e presença de esferóides axonais (Soto-Blanco et al. 2002 a,b, 2004), como também aumento no número de vacúolos de reabsorção no colóide dos folículos tireoideanos (Soto-Blanco et al. 2001, 2004, Sousa et al. 2002). As plantas cianogênicas podem também produzir degeneração hidrópica das células epiteliais dos túbulos renais e hepatócitos em ratos, após uma exposição prolongada ao cianeto de potássio (Sousa et al. 2002). Além das lesões mencionadas, têm sido observadas mielomalacia, caracterizada por incontinência urinária, alopecia devido a queimaduras pela urina, e incoordenação dos membros posteriores em bovinos, ovinos e equïinos que pastam Sorghum sudanense (capim-Sudão ou capim-Sudão híbrido) e artrogripose em fetos, causando distocia em mães que pastam Sorghum spp (Radostits et al. 2000). Em trabalhos preliminares nos que foi administrada uma dose diária de $2,6 \mathrm{~g} / \mathrm{kg}$ a dois cabritos por um período de 60 dias o único sinal clínico observado em um animal após os 30 dias foi salivação excessiva durante a administração da planta. Não foram observadas lesões significantes na necropsia nem no estudo histológico de um dos cabritos sacrificados ao final do experimento (Amorim et al. 2004, dados não publicados).

\section{REFERÊNCIAS}

Alvariza F.R.1993. Intoxicação por nitratos e nitritos, p.291-297. In: RietCorrea F., Mendez M.D.C \& Schild A.L. (ed.) Intoxicação por Plantas e Micotoxicoses em Animais Domésticos. Editora Agropecuária Hemisfério Sul do Brasil, Pelotas, RS.

Amorim S.L., Medeiros R.M.T., Riet-Correa F. \& Oliveira A.C.P. 2004. Estudo experimental com plantas cianogênicas em bovinos. Pesq. Vet. Bras. 24 (Supl.):5-6.

Aplin T.E.H. 1976. Cyanogenectic plants of Western Australia. Bull. 3967, Western Australian Department of Agriculture. 14p.

Araújo G.G.L., Albuquerque S.G. \& Guimarães F.C. 2001. Opções no uso de forrageiras arbustivo-arbóreas na alimentação animal no semi-árido do Nordeste, p.111-137. In: Carvalho M.M., Alvim M.J. \& Carneiro J.C. (ed.) Sistema Agroflorestais Pecuários: opções de sustentabilidade para áreas tropicais e subtropicais. Embrapa Gado de Leite, Juiz de Fora, MG.

Brito M.F., França T. N., Oliveira K. D. \& Cerqueira V. D. 2000. Estudos experimentais em coelhos com plantas cianogênicas. Pesq.Vet. Bras. 20(2):65-70

Canella C.F.C., Döbereiner J. \& Tokarnia C.H. 1968. Intoxicação experimental pela maniçoba (Manihot glaziovii Muell. Arg.) em bovinos. Pesq. Agropec. Bras. 3:347-350

Cereda M.P. 2003. Processamento da mandioca como mecanismo de detoxificação, p.47-81. In: Cereda M.P. \& Vilpoux, O.F. (ed.) Tecnologia, Usos e Potencialidades de Tuberosos Amilácias. Vol. 3. Série Culturas de Tuberosas Amilácias Latino-Americanas. Fundação Cargill, São Paulo.
Diaz A.M.P., Portus M.I.G. \& Silva M.F. da. 1978. Algumas plantas cianogênicas da Região Amazônica. Acta Amazônica, Manaus, 8(4):67985.

Everist S.L. 1974. Poisonous Plants of Australia. Angus and Robertson, Sidney.

Gava A., Stolft L., Neves D.S., Stolft O., Varaschim M.S. \& Ferreira F.M.M. 1992. Intoxicação experimental por Prunus sellowi (Rosaceae) em bovinos. Pesq. Vet. Bras. 12(1/2):1-4.

Kingsbury J.M. 1964. Poisonous Plants of the United States and Canada. Prentice-Hall, Englewood Cliffs, New Jersey.

Medeiros R.M.T., Nobre V.M.T., Tabosa I.M \& Riet-Correa F. 2000. Toxic plants for ruminants in the state of Paraíba, northeastern Brazil. 21st World Buiatrics Uruguay, in CD-ROM, p.10141-10150.

Mendez M.D.C. 1993. Intoxicação por plantas cianogênicas, p.279-284. In: Riet-Correa F., Mendez M.D.C \& Schild A.L. (ed.) Intoxicação por Plantas e Micotoxicoses em Animais Domésticos. Editora Agropecuária Hemisfério Sul do Brasil, Pelotas, RS.

Radostits O.M., Gay C.C., Blood D.C. \& Hinchcliff K.W. 2000. Clínica Veterinária: um tratado de doenças de bovinos, ovinos, caprinos, suínos e eqüídeos. 9a edição. W.B. Saunders, London, p.1631-1636.

Riet-Correa F. \& Medeiros R.M.T. 2001. Intoxicações por plantas no Brasil e no Uruguai: importância econômica, controle e riscos para a saúde pública. Pesq. Vet. Bras. 21(1):38-42

Smith B.P. 1994. Tratado de Medicina Interna de Grandes Animais. Vol. 2. Editora Manole, São Paulo, p.1642-1643.

Soto-Blanco B., Schumaher-Henrique B. \& Górniak S.L. 2004. Toxicidade da administração prolongada das folhas de mandioca (Manihot esculenta Crantz) a cabras adultas. Pesq. Vet .Bras. 24 (Supl.):71-72.

Soto-Blanco B., Maiorka P.C. \& Górniak S.L. 2002a. Effects of long-term low-dose cyanide administration to rats. Ecotoxicol. Environ. Saft. 53 (1):37-41.

Soto-Blanco B., Maiork P.C. \& Górniak S.L. 2002b. Neuropathologic study of long term cyanid administration to goat. Food Chem. Toxicol. 40(11):1693-1698

Soto-Blanco B., Gorniak S.L. \& Kimura E.T. 2001. Physiopathological effects of the administration of chronic cyanide to growing goats a model for ingestion of cyanogenic plants. Vet. Res. Commun. 25(5):379-89.

Sousa A.B., Soto-Blanco B., Guerrra J.L., Kimura E.T. \& Górniak S.L. 2002. Does prolonged oral exposure to cyanide promote hepatotoxicity and nephrotoxicity. Toxicology 24:(2):87-95

Tokarnia C.H., Peixoto P.V. \& Döbereiner J. 1994. Intoxicação experimental por Piptadenia macrocarpa (Leg.Mimosoideae) em bovinos. Pesq. Vet. Bras. 12(2/3):57-63.

Tokarnia C.H., Peixoto P.V., Brito M.F., Duarte M.D. \& Brust L.A.C. 1999. Estudos experimentais com plantas cianogênicas em bovinos. Pesq. Vet. Bras. 19(2):84-90.

Tokarnia C.H., Döbereiner J. \& Peixoto P.V. 2000. Plantas Tóxicas do Brasil. Editora Helianthus, Rio de Janeiro, p.215-221.

Van der Walt S.J. 1944. Some aspects of the toxicology of hydrocyanic acid in ruminants. Onderstepoort J. Vet. Sci. Anim. Ind. 19(1/2):79-160.

Vennesland B., Castric, P.A., Conn E.E., Solomonson L., Violni M. \& Westley J. 1982. Cyanide metabolism. Federation Proceedings, Berlin, 41(10):2639. 